\title{
Testosterone treatment is not associated with increased risk of prostate cancer or worsening of lower urinary tract symptoms: prostate health outcomes in the Registry of Hypogonadism in Men
}

\author{
Frans M.J. Debruyne*, Hermann M. Behre ${ }^{\dagger}$, Claus G. Roehrborn ${ }^{\ddagger}$, Mario Maggi§, \\ Frederick C.W. Wu", Fritz H. Schröder**, Thomas Hugh Jones ${ }^{\dagger \dagger}$, Hartmut Porst ${ }^{+\ddagger}$, \\ Geoffrey Hackett $\$$, Olivia A. Wheaton ${ }^{4 \pi}$, Antonio Martin-Morales***, Eric J.

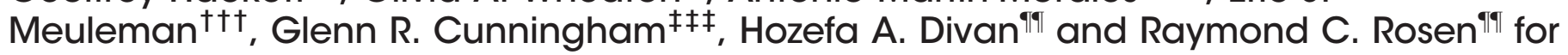 \\ the RHYME Investigators
}

*Andros Men's Health Institutes, Arnhem, The Netherlands, 'Center for Reproductive Medicine and Andrology, Martin Luther University Halle-Wittenberg, Halle, Germany, "Southwestern Medical Center, University of Texas, Dallas, TX, USA, ${ }^{\S}$ Sexual Medicine and Andrology Unit, Department of Experimental and Clinical Biomedical Sciences, University of Florence, Florence, Italy, "University of Manchester, Manchester, UK, **Erasmus Medical Center, Rotterdam, The Netherlands, "'Barnsley Hospital NHS Foundation Trust, Barnsley, UK, "F Private Practice of Urology/Andrology, Hamburg, Germany, 'ss Holly Cottage Clinic, Lichfield, Staffordshire, UK, "New England Research Institutes, Inc., Watertown, MA, USA, ***Carlos Haya University Hospital, Málaga, Spain, "tt VU Medical Center, Amsterdam, The Netherlands, and F Baylor College of Medicine, St. Luke's Episcopal Hospital, Houston, TX, USA

\section{Objectives}

To evaluate the effects of testosterone-replacement therapy (TRT) on prostate health indicators in hypogonadal men, including rates of prostate cancer diagnoses, changes in prostate-specific antigen (PSA) levels and lower urinary tract symptoms (LUTS) over time.

\section{Patients and Methods}

The Registry of Hypogonadism in Men (RHYME) is a multinational patient registry of treated and untreated, newlydiagnosed hypogonadal men $(n=999)$. Follow-up assessments were performed at 3-6, 12, 24, and 36 months. Baseline and follow-up data collection included medical history, physical examination, blood sampling, and patient questionnaires. Prostate biopsies underwent blinded independent adjudication for the presence and severity of prostate cancer; PSA and testosterone levels were measured via local and central laboratory assays; and LUTS severity was assessed via the International Prostate Symptom Score (IPSS). Incidence rates per 100000 person-years were calculated. Longitudinal mixed models were used to assess effects of testosterone on PSA levels and IPSS.

\section{Results}

Of the 999 men with clinically diagnosed hypogonadism (HG), 750 (75\%) initiated TRT, contributing 23900 person-months of exposure. The mean testosterone levels increased from 8.3 to $15.4 \mathrm{nmol} / \mathrm{L}$ in treated men, compared to only a slight increase from 9.4 to $11.3 \mathrm{nmol} / \mathrm{L}$ in untreated men. In all, 55 biopsies were performed for suspected prostate cancer, and 12 non-cancer related biopsies were performed for other reasons. Overall, the proportion of positive biopsies was nearly identical in men on TRT $(37.5 \%)$ compared to those not on TRT $(37.0 \%)$ over the course of the study. There were no differences in PSA levels, total IPSS, or the IPSS obstructive sub-scale score by TRT status. Lower IPSS irritative sub-scale scores were reported in treated compared to untreated men.

\section{Conclusions}

Results support prostate safety of TRT in newly diagnosed men with HG.

\section{Keywords}

testosterone, hypogonadism, disease registry, benign prostatic hyperplasia, \#ProstateCancer, \#PCSM

\section{Introduction}

Hypogonadism (HG) due to testicular or non-testicular causes affects $\sim 2.1 \%$ of men aged $\geq 40$ years, increasing to
$3.2 \%$ and $5.1 \%$ in men aged $60-69$ and $70-79$ years, respectively $[1,2]$. Prevalence is $2-3$ times higher in men with type 2 diabetes or other components of the metabolic syndrome $[3,4]$. The recommended treatment for 
biochemically confirmed HG is testosterone-replacement therapy (TRT), which can be administered via multiple injectable, implantable, topical or oral formulations [5-7]. In addition to symptomatic improvements [8-10], possible benefits for TRT include reduction in body mass index (BMI) and waist size, improved glycaemic control and lipid profile, in addition to improvements in body composition, bone mineralisation, and other cardio-metabolic indices [11-14].

Prostate cancer growth and BPH progression have long been seen as major risks associated with TRT, with current guidelines contraindicating TRT in men with a history of prostate cancer or advanced $\mathrm{BPH}$ [5-7]. In contrast, findings from very recent studies raise serious doubts about the pathological role of TRT in either prostate cancer or BPH. Snyder et al. [15] recently reported results of a large, National Institutes of Health-funded, randomised trial of topical testosterone compared with placebo in 800 men aged $>65$ years with symptomatic HG. No evidence of BPH progression or increased prostate cancer incidence was seen over 12 months of treatment. Similar findings were reported in a pooled, 5-year analysis of three single-centre, longitudinal patient registries [16]. Prostate cancer rates among men on TRT in this pooled analysis were lower than previously reported for European men in this age category [17]. Independent systematic reviews have similarly concluded that affirmative evidence is lacking for either prostate cancer risk $[18]$ or BPH progression $[19,20]$ in association with TRT. On the other hand, design flaws, including lack of untreated controls or independent adjudication of clinical outcomes, inadequate sample sizes, and short duration of follow-up are key weaknesses in previously published studies.

The Registry of Hypogonadism in Men (RHYME) is a large, multi-national prospective registry of men with HG, which was designed and powered specifically to assess prostate cancer outcomes in men with HG receiving TRT compared with untreated men with HG or general population estimates. The primary aim was to examine prospectively the association between TRT and prostate health outcomes, including prostate cancer incidence and $\mathrm{BPH}$ progression in hypogonadal men naive to TRT who are diagnosed and treated according to current standard-of-care guidelines.

\section{Patients and Methods}

Registry of Hypogonadism in Men is an observational, noninterventional disease registry with longitudinal data collection in a large sample of clinically diagnosed, wellcharacterised men with HG. Eligibility criteria included men aged $\geq 18$ years with a diagnosis of $\mathrm{HG}$, confirmed by abnormal testosterone levels on at least two occasions. Physicians were encouraged to apply guideline

recommendations of total serum testosterone of $<12.1 \mathrm{nmol} /$ $\mathrm{L}$; free testosterone of $<243 \mathrm{pmol} / \mathrm{L}$, and a report of bothersome symptoms by the patient [6,7]. Men were excluded if they had received prior TRT with any product or a past history of breast or prostate cancer, high-grade prostatic intraepithelial neoplasia, radical prostatectomy or life-expectancy shorter than 24 months as judged by the clinical site investigator. Men with major psychiatric disorders, drug or alcohol abuse or gender dysphoria were also excluded. All eligible men were enrolled consecutively, a key element of the design for reducing selection bias.

Each patient enrolled was scheduled for at least four and up to five assessments over a minimum of 2 years starting at baseline and then the following 3-6, 12, 24 and 36 months. Additional diagnostic tests or procedures, including prostate biopsy or ultrasonography, were determined by the treating physician in consultation with the patient. This clinical decision-making paradigm was designed intentionally to reflect clinical practice in order to increase generalisability of RHYME findings, being consistent with the

non-interventional nature of a registry design. Further details of the registry design and methods have been published previously [21].

Patient enrolment was initiated in 2009 and completed in 2011. On 30 September 2013, the registry was closed to patient follow-up. In all, 25 clinical sites in six European countries (Germany, Italy, The Netherlands, Spain, Sweden, and UK) participated in enrolment. Site investigators included approximately equal number of urologists (13) and endocrinologists or general physicians (12). All the men provided written informed consent before enrolment. Registry protocols were approved by local Ethics Committees at each clinical site.

The primary endpoint for RHYME was the proportion of positive prostate biopsies observed after 2 years. For our primary statistical comparison, we assumed that the expected positive biopsy rate under the null hypothesis of no effect of TRT would be $\sim 30 \%$, based on prevalence rates for similar aged men in large, community-based studies [17,22-24]. Secondary aims of the registry were to examine changes in PSA, LUTS, and other health outcomes. Data were collected through abstraction of medical records and a selfadministered questionnaire designed to obtain information on demographic characteristics, lifestyle factors (e.g., smoking, physical activity), and other health information (prostaterelated symptoms, health-related quality of life) using standardised instruments, including the IPSS. Local laboratory assays (testosterone, LH, PSA), were obtained by site investigators and used for determining eligibility and treatment response, while independent central laboratory assays were obtained for blinded evaluation of treatment outcomes.

All prostate-biopsy reports, prostatectomy findings and relevant supporting documents were reviewed by an 
independent Clinical Endpoints Committee (CEC Members: C. Roehrborn (Chair), F. Schröder, G. Cunningham, G. Jackson) and used for research purposes only. The adjudication process by the committee included blinded review of clinical data and pathology reports. The committee adjudicated de-identified biopsy reports and prostatectomy findings as 'positive' or 'negative' for prostate cancer. Adjudication included determination of the final Gleason score and T-Stage classification, based on review of the pathology findings. DRE and TRUS were performed only as medically indicated. Reasons for biopsy requests were recorded (e.g., PSA level rise, elevated PSA level, abnormal DRE or TRUS findings) in addition to details of prostate surgery or other treatments. Urogenital surgical procedures and cancer-related outcomes were monitored at every study visit.

\section{Statistical Analyses}

Men were considered 'treated' if they were on active TRT at one or more visits during the study period. Conversely, untreated subjects did not receive TRT at any time during the period of monitoring. Descriptive statistics (i.e. means, standard deviation [SD]) were used for assessing baseline characteristics and testosterone use. Person-time of exposure was calculated as the time up to prostate cancer diagnosis or final contact. Prostate cancer incidence rates for treated and untreated men were calculated as the number of events divided by the total person-time, multiplying by 100000 .

Longitudinal mixed-model analyses evaluated changes in outcome variables (i.e. PSA level, IPSS) by treatment, time, and the interaction of time and treatment accounting for repeated, correlated observations in the same patient. TRT was treated as time-varying. PSA level and IPSS outcomes were log-transformed and treated as time-varying. Using baseline measured covariates, multivariate modelling was used to control for potential confounders. All covariates were entered into single multivariate models predicting each outcome; those with a $P \leq 0.2$ in each model were selected as final covariates for the fully adjusted model.

\section{Results}

Of the 1006 men enrolled, seven were ineligible, resulting in an analytic cohort of 999 patients (Fig. 1). In all, 71 men discontinued the study, resulting in a patient retention rate of $92.9 \%$ over 3 years of follow-up. Approximately 23900 person-months were accrued, which represented $99.6 \%$ of the targeted follow-up period.

The mean (SD) age was 59.1 (10.5) years; treated and untreated men did not differ in age, type of HG (primary vs secondary) or other sociodemographic characteristics (Table 1). Men receiving TRT had a higher prevalence of HG symptoms, erectile dysfunction, urological and psychiatric conditions prior to enrolment than untreated men, although medication use at baseline was similar across the two groups. About $40 \%$ of both groups had moderate-to-severe LUTS (IPSS $>8$ ) at baseline. Prior negative biopsies were recorded for $19(2.5 \%)$ treated men and $18(7.2 \%)$ untreated men and a higher percentage of past abnormal DREs were reported for untreated (38.2\%) compared to treated (23.3\%) men.

\section{Testosterone Administration and Compliance with Treatment}

In all, $750(75 \%)$ men received a prescription for TRT and 249 (25\%) did not receive TRT in any form. Testosterone prescriptions were mostly for topical gels $(68 \%)$ or injectables (31\%), with only $2 \%$ receiving orally administered drugs. Most of the treated men (70\%) were consistent users (every study visit after baseline) with a low treatment discontinuation rate of only $17 \%$. About $16 \%$ of men on TRT received testosterone at only one visit. Most of the treated men (75\%) received testosterone at two or more consecutive visits. Patterns were similar for topical and injectable testosterone use. Most oral users (75\%) used testosterone at three consecutive visits.

As shown in Fig. 1, the mean (SD) total testosterone concentration was $8.3(3.9) \mathrm{nmol} / \mathrm{L}$ before TRT in the cohort of treated men, which increased to $15.4(10.4) \mathrm{nmol} / \mathrm{L}$ at follow-up. In contrast, untreated men had a mean (SD) baseline total testosterone concentration of $9.4(3.7) \mathrm{nmol} / \mathrm{L}$, which increased to $11.3(6.0) \mathrm{nmol} / \mathrm{L}$ at follow-up.

\section{Primary Outcome: Positive Biopsy Rates and Prostate Cancer Incidence}

In all, 55 for cause prostate biopsies and 12 incidental prostatectomies were performed on RHYME participants during the period of follow up (Table 2). The most common triggering events for biopsy referral were PSA level rise and/ or abnormally high PSA level, followed by an abnormal DRE for both negatively and positively adjudicated biopsies. Most biopsies were taken during the first 12 months following enrolment. The positive biopsy rate was $37.5 \%$ in treated and $37.0 \%$ in untreated men. Oncological grading was performed on 25 positive biopsies; Gleason scores of $<7$ were observed in 14/18 (77.8\%) positive biopsies in the treated group and 4/ 7 in the untreated group. No prostate cancer-related deaths were reported.

The overall prostate cancer incidence rate (1221.4 per 100000 person-years) was comparable to the general population (1251.9 per 100000 person-years) (Table 3). The incidence rate in men aged $\geq 60$ years was 2030.1 per 100000 person-years. The incidence rate in untreated men aged $\geq 60$ years was higher compared to treated men (3941.6 vs 
Fig. 1 Patient disposition and testosterone-replacement therapy (TRT) patterns of use.

Patients enrolled into the Registry from 2005 to 2011

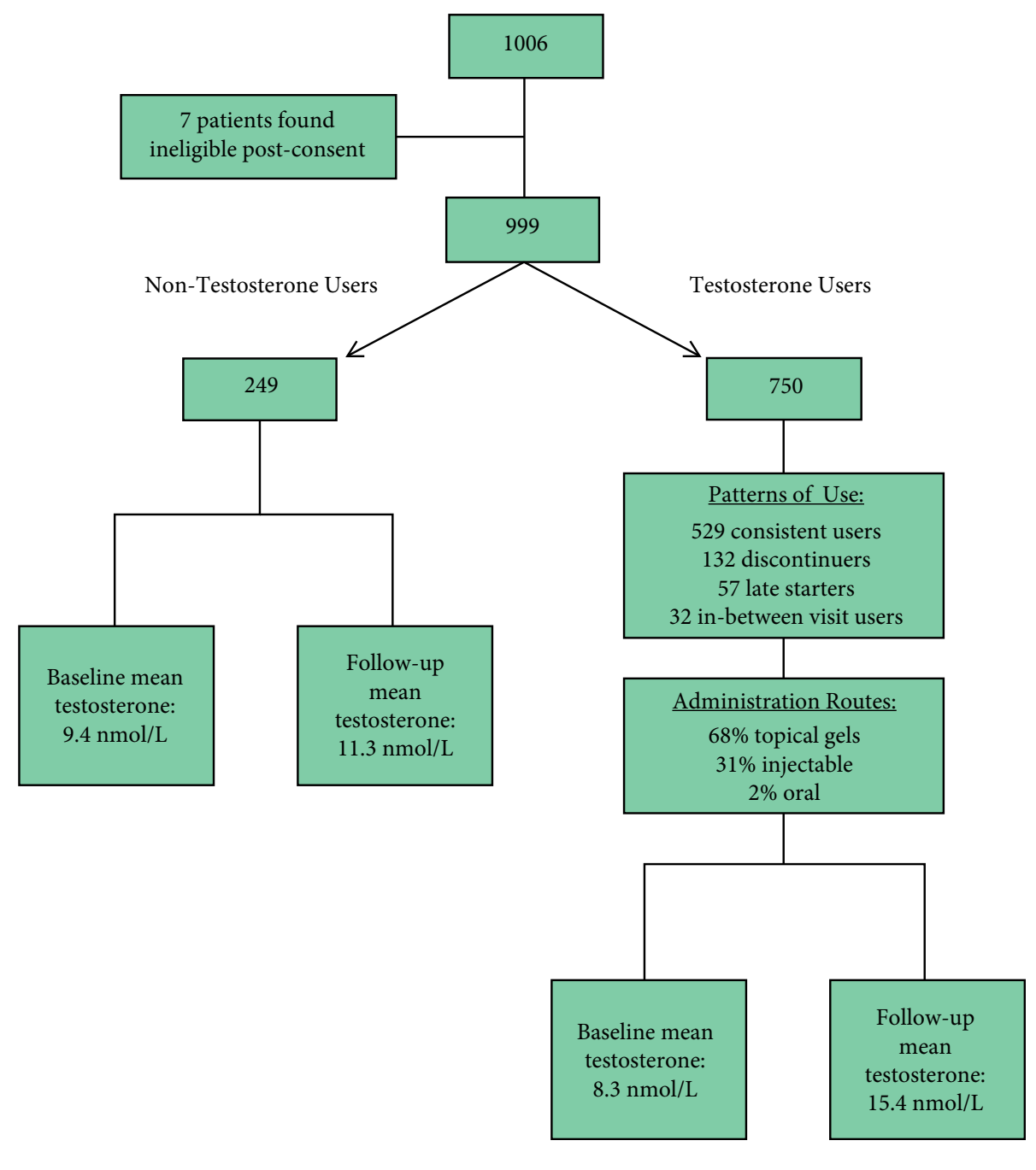

1582.5 per 100000 person-years, respectively), although not statistically different $(P=0.07)$. The incidence rate ratio (RR) in treated compared with untreated men $(0.52,95 \%$ CI 0.22 , 1.26) showed no increased prostate cancer risk associated with TRT.

\section{Secondary Outcomes: Treatment Effects on PSA Levels and IPSS}

Baseline unadjusted PSA levels were slightly higher for untreated than treated men, at a mean (SD) of 2.2 (9.1) ng/ $\mathrm{mL}$ vs $1.1(1.7) \mathrm{ng} / \mathrm{mL}$ (Table 1). Changes in PSA levels over time in both treatment groups are shown in Fig. 2. As shown, adjusted PSA values increased slightly over the first 12 months of follow-up in men receiving TRT, but remained stable at 24 months. Based on the longitudinal mixed-model statistical analyses (Table 4), PSA levels were significantly higher overall among men receiving TRT compared with untreated men $(P<0.001)$; however, the interaction between time and treatment was not significant.

Moderate-to-severe LUTS (IPSS $\geq 8$ ) were reported at baseline by $38.3 \%$ and $41.1 \%$ respectively of untreated and treated men. As shown in Fig. 3, untreated men showed a slight increase in adjusted total IPSS over time, although little change was seen overall in either group (Fig. 3). Adjusted and unadjusted longitudinal models showed modest, positive effects of TRT on LUTS, with 7.1\% lower total IPSS over time $(P=0.004)$ and $7.9 \%$ lower irritative scores $(P<0.001)$ in treated compared with untreated men, but no change in IPSS obstructive scores $(P=0.33$; Table 4$)$.

\section{Discussion}

In this large, multi-national registry of men with $\mathrm{HG}$, we found no evidence of increased rates of prostate cancer 
Table 1 Cohort baseline characteristics according to subsequent testosterone-replacement therapy (TRT) status.

\begin{tabular}{|c|c|c|c|c|c|}
\hline \multirow[t]{2}{*}{ Baseline characteristic } & \multirow[t]{2}{*}{$\mathbf{N}^{*}$} & \multirow{2}{*}{$\begin{array}{c}\text { Overall cohort } \\
\text { n (\%) or mean } \pm \text { SD }\end{array}$} & \multicolumn{3}{|c|}{ TRT status } \\
\hline & & & $\begin{array}{l}\text { Untreated }(n=249) \\
n(\%) \text { or mean } \pm \text { SD }\end{array}$ & $\begin{array}{l}\text { Treated }(n=750) \\
n(\%) \text { or mean } \pm \text { SD }\end{array}$ & $\boldsymbol{P}$ \\
\hline Age, years & 999 & $59.1 \pm 10.5$ & $59.7 \pm 11.1$ & $58.9 \pm 10.3$ & 0.30 \\
\hline Age group & 999 & & & & 0.27 \\
\hline$<60$ years & & $516(51.7)$ & $121(48.6)$ & $395(52.7)$ & \\
\hline$\geq 60$ years & & $483(48.4)$ & $128(51.4)$ & $355(47.3)$ & \\
\hline Type of HG & 751 & & & & 0.26 \\
\hline Primary HG (LH $\geq 7.6$ IU/L) & & $135(18.0)$ & $39(20.7)$ & $96(17.1)$ & \\
\hline Secondary HG (LH < 7.6 IU/L) & & $616(82.0)$ & $149(79.3)$ & $467(83.0)$ & \\
\hline BMI & 989 & $30.0 \pm 5.5$ & $29.4 \pm 5.1$ & $30.2 \pm 5.7$ & 0.04 \\
\hline Past surgeries/therapy & 999 & & & & \\
\hline Orchidectomy & & $27(2.7)$ & $1(0.4)$ & $26(3.5)$ & 0.01 \\
\hline Orchidopexy & & $18(1.8)$ & $4(1.6)$ & $14(1.9)$ & 0.76 \\
\hline Pituitary surgery & & $28(2.8)$ & $5(2.0)$ & $23(3.1)$ & 0.36 \\
\hline Radiotherapy & & $17(1.7)$ & $3(1.2)$ & $14(1.9)$ & 0.46 \\
\hline HG symptoms at time of diagnosis & 999 & & & & \\
\hline Erectile dysfunction & & $622(62.3)$ & $140(56.2)$ & $482(64.4)$ & 0.02 \\
\hline Decreased desire for sex & & $116(11.6)$ & $26(10.4)$ & $90(12.0)$ & 0.49 \\
\hline Fatigue/weakness & & $100(10.0)$ & $36(14.5)$ & $64(8.5)$ & 0.01 \\
\hline Infertility & & $39(3.9)$ & $18(7.2)$ & $21(2.8)$ & $<0.01$ \\
\hline Gynecomastia & 979 & $98(10.0)$ & $17(6.9)$ & $81(11.1)$ & 0.06 \\
\hline Baseline comorbidities & 999 & & & & \\
\hline Urological disease $^{\dagger}$ & & $742(74.3)$ & $169(67.9)$ & $573(76.4)$ & 0.01 \\
\hline Endocrine disease $\mathrm{e}^{\ddagger}$ & & $532(53.3)$ & $129(51.8)$ & $403(53.7)$ & 0.60 \\
\hline Cardiovascular disorder & & $515(51.6)$ & $125(50.2)$ & $390(52.1)$ & 0.60 \\
\hline Pulmonary disease & & $130(13.0)$ & $29(11.6)$ & NA & - \\
\hline Psychiatric disease & & $151(15.1)$ & $24(9.6)$ & $127(16.9)$ & 0.01 \\
\hline Concomitant medications & 999 & & & & \\
\hline Anti-hypertensive medications & & 495 (49.5) & $119(47.8)$ & $376(50.1)$ & 0.53 \\
\hline Lipid lowering medications & & $391(39.1)$ & $89(35.7)$ & $302(40.3)$ & 0.20 \\
\hline Anti-diabetes medications & & $257(25.7)$ & $65(26.1)$ & $192(25.6)$ & 0.88 \\
\hline Erectile dysfunction medications & & $253(25.3)$ & $60(24.1)$ & $193(25.7)$ & 0.62 \\
\hline Peptic ulcer medications & & $180(18.0)$ & $41(16.5)$ & $139(18.5)$ & 0.48 \\
\hline LUTS severity (total IPSS) & 980 & & & & 0.87 \\
\hline None to mild $(<8)$ & & $584(59.6)$ & $148(61.7)$ & $436(58.9)$ & \\
\hline Moderate (8-19) & & $308(31.4)$ & $73(30.4)$ & $235(31.8)$ & \\
\hline Severe $(\geq 20)$ & & $88(9.0)$ & $19(7.9)$ & $69(9.3)$ & \\
\hline Erectile dysfunction (IIEF score) & 981 & & & & $<0.01$ \\
\hline None to mild $(\geq 22)$ & & $343(35.0)$ & $104(43.5)$ & $239(32.2)$ & \\
\hline Moderate to severe $(<22)$ & & $638(65.0)$ & $135(56.5)$ & $503(67.8)$ & \\
\hline Past prostate biopsies & 999 & $37(3.7)$ & $18(7.2)$ & $19(2.5)$ & $<0.001$ \\
\hline Past DRE & 999 & $774(77.5)$ & $181(73.0)$ & $593(79.1)$ & 0.05 \\
\hline Abnormal result & 774 & $195(25.2)$ & $57(31.5)$ & $138(23.3)$ & 0.03 \\
\hline Male kin with prostate cancer & 987 & $56(5.7)$ & $18(7.3)$ & $38(5.1)$ & 0.19 \\
\hline
\end{tabular}

IIEF, International Index of Erectile Function. ${ }^{*}$ Numbers vary for variables with missing data or indeterminate laboratory findings. ${ }^{\dagger}$ Urological disease included ejaculatory disorder, erectile dysfunction, Peyronie's disease, BPH, prostatitis and testicular cancer. ${ }^{7}$ Endocrine disease included diabetes, dyslipidaemia, thyroid or parathyroid disorder, adrenal disorder, pituitary disorder, and multiple endocrine neoplasia.

diagnoses in men receiving TRT compared to untreated men in the registry. Based on blinded, independent adjudication of 67 prostate biopsies over 23900 person-months of follow-up, we observed almost identical unadjusted rates of positive biopsies; $37.5 \%$ in men receiving TRT, compared with $37.0 \%$ in untreated men. As the denominator (i.e., person-months of observation) is higher in men receiving TRT compared with untreated men, an overall trend towards a lower adjusted incidence rate of positive biopsies was seen among men receiving TRT compared with untreated men (adjusted RR $0.52,95 \%$ CI $0.22,1.26$ ). There were no differences in prostate cancer grade or severity in men on TRT compared with untreated men or prostate cancer rates in the general population. Abnormal DRE rates and referrals for other urological procedures were similar in both groups, although a trend was seen towards decreased irritative scores and total IPSS in men receiving TRT compared with untreated men. Overall, we found no evidence of increased risk of BPH progression or prostate cancer incidence or severity in men receiving TRT in RHYME. Minor differences were noted in PSA levels and IPSS in treated and untreated men, which are not likely of clinical significance.

Similarly, TRT administration did not result in an increase in prostate cancer or LUTS/BPH in a pooled analysis of three single-centre, longitudinal patient registries [16]. Moreover, 
Table 2 Biopsy findings according to testosterone-replacement therapy (TRT) status (total number of biopsies 67).

\begin{tabular}{|c|c|c|c|}
\hline Variable & $\begin{array}{c}\text { Negative } \\
\text { biopsy } \\
(n=42)\end{array}$ & $\begin{array}{l}\text { Positive } \\
\text { biopsy } \\
(n=25)\end{array}$ & $\boldsymbol{P}$ \\
\hline \multicolumn{4}{|l|}{$N(\%)$} \\
\hline \multicolumn{4}{|l|}{ TRT status } \\
\hline Treated & $30(71.4)$ & $18(72.0)$ & 0.96 \\
\hline Untreated & $12(28.6)$ & $7(28.0)$ & \\
\hline $\begin{array}{l}\text { Study visit closest to prostate } \\
\text { biopsy, months }\end{array}$ & & & 0.32 \\
\hline Baseline & $2(4.8)$ & $1(4.0)$ & \\
\hline $3-6$ & $6(14.3)$ & $9(36.0)$ & \\
\hline 12 & $18(42.9)$ & $8(32.0)$ & \\
\hline 24 & $9(24.3)$ & $5(20.0)$ & \\
\hline 36 & $7(16.7)$ & $2(8.0)$ & \\
\hline \multicolumn{4}{|l|}{ Reason(s) for prostate biopsy* } \\
\hline PSA level rise & $18(54.6)$ & $15(68.2)$ & 0.28 \\
\hline Abnormally high PSA level & $26(78.8)$ & $15(68.2)$ & 0.34 \\
\hline Abnormal TRUS & $3(9.1)$ & $1(4.6)$ & 0.50 \\
\hline Abnormal DRE & $12(36.4)$ & $9(40.9)$ & 0.72 \\
\hline Other & $0(0.0)$ & $0(0.0)$ & - \\
\hline Procedure type & & & 0.21 \\
\hline TRUS-guided biopsy & $21(50.0)$ & $16(64.0)$ & \\
\hline $\begin{array}{l}\text { Transperineal ultrasound } \\
\text { guided biopsy }\end{array}$ & $14(33.3)$ & $4(16.0)$ & \\
\hline Other biopsy procedure & $0(0.0)$ & $1(4.0)$ & \\
\hline Total (radical) prostatectomy & $0(0.0)$ & $1(4.0)$ & \\
\hline Partial prostatectomy & $7(16.7)$ & $3(12.0)$ & \\
\hline \multicolumn{4}{|l|}{$\begin{array}{l}\text { PSA level at time of } \\
\text { biopsy }(n=47)\end{array}$} \\
\hline Mean (SD), ng/mL & $4.0(3.8)$ & $11.1(30.4)$ & 0.20 \\
\hline Median (interquartile range), $\mathrm{ng} / \mathrm{mL}$ & $3.2(1.7,4.0)$ & $3.2(1.8,5.8)$ & - \\
\hline PSA level $\geq 3.0 \mathrm{ng} / \mathrm{mL}$ & & & 0.93 \\
\hline Yes & $17(54.8)$ & $9(56.3)$ & \\
\hline No & $14(45.2)$ & $7(43.8)$ & \\
\hline
\end{tabular}

${ }^{*}$ Multiple indicators were recorded as necessary.

Table 3 Prostate cancer (positive biopsy) incidence rates by testosteronereplacement therapy (TRT) status.

\begin{tabular}{|c|c|c|c|c|}
\hline & $\begin{array}{l}\text { Overall } \\
(n=999)\end{array}$ & $\begin{array}{l}\text { Untreated } \\
(n=249)\end{array}$ & $\begin{array}{l}\text { Treated } \\
(n=750)\end{array}$ & $P$ \\
\hline Overall events, $n$ & 25 & 7 & 18 & - \\
\hline Person-years & 2046.9 & 348.4 & 1698.5 & - \\
\hline $\begin{array}{r}\text { Incidence rate } \\
\text { (per } 100000 \\
\text { person-years) }\end{array}$ & 1221.4 & 2009.2 & 1059.8 & 0.17 \\
\hline \multicolumn{5}{|l|}{$\begin{array}{l}\text { Aged }<60 \text { years } \\
\text { population }\end{array}$} \\
\hline Overall events, $n$ & 6 & 0 & 6 & - \\
\hline Person-years & 1111.0 & 0 & 940.2 & - \\
\hline $\begin{array}{r}\text { Incidence rate } \\
\text { (per } 100000 \\
\text { person-years) }\end{array}$ & 540.1 & 0 & 638.2 & $\mathrm{NR}^{*}$ \\
\hline \multicolumn{5}{|l|}{$\begin{array}{l}\text { Aged } \geq 60 \text { years } \\
\text { population }\end{array}$} \\
\hline Overall events, $n$ & 19 & 7 & 12 & - \\
\hline Person-years & 935.9 & 177.6 & 758.3 & - \\
\hline $\begin{array}{r}\text { Incidence rate } \\
\text { (per } 100000 \\
\text { person-years) }\end{array}$ & 2030.1 & 3941.6 & 1582.5 & 0.07 \\
\hline
\end{tabular}

${ }^{*} N R$, not reportable; no comparison of rates can be made for this age group, as there were no cases reported in the $<60$-years age group of untreated men. recent unpublished 8-year follow-up data from this ongoing study shows a higher rate of incident prostate cancer and more aggressive tumours among untreated men compared with those on TRT [25]. Other registry studies have observed similar findings for long-term TRT effects on PSA and LUTS [26-30]. In one large observational study [27], 1140 men received testosterone undecanoate injections during an observation period of 9-12 months. The mean (SD) PSA levels increased slightly from $1.1(0.9) \mathrm{ng} / \mathrm{mL}$ at baseline to $1.3(1.2) \mathrm{ng} / \mathrm{mL}$ at 24 weeks, and then remained stable [27]. The Testim ${ }^{\circledR}$ Registry in the United States (TRiUS) Registry observed similar slight increases in PSA levels [29]. Other studies have reported mild improvements in voiding symptoms or LUTS following TRT [19,26,30]. A recent systematic review noted that evidence is lacking of consistent effects of TRT on LUTS [20], although there are indications in some studies, including RHYME, of modest improvements in men with LUTS who receive TRT $[26,29]$.

This lack of an association between serum testosterone and prostate cancer risk has similarly been confirmed in the placebo arms of both the REduction by DUtasteride of prostate Cancer Events (REDUCE) [31] and Prostate Cancer Prevention Trial (PCPT) trials [32]. In reviewing these findings, a new hypothesis has been advanced that the magnitude of age-related declines in testosterone, rather than a static level of testosterone measured at a single time-point may trigger or promote the development of prostate cancer [33]. Other studies have similarly reported higher rates of high-grade prostate cancer in men with sub-normal testosterone levels [34-36].

While the traditional view of endogenous or exogenous testosterone as a potential trigger or 'biological fuel' for prostate enlargement or cancer growth has been sharply contested in recent years [37], concerns remain among physicians and the public about prostate safety of TRT [3840]. Controlled trials of TRT have been under-powered or too short in duration to adequately assess safety risks [15]. Moreover, patient selection factors and clinical trial constraints can limit generalisability of trial results. Systematic reviews and meta-analyses have also failed to provide definitive outcome data regarding the potential risk of prostate cancer or other adverse outcomes [8,18-20]. In contrast, a well-designed patient registry offers advantages for assessing both clinical benefits and long-term safety outcomes in a more naturalistic, 'real-world' setting [41].

Major strengths of the present study include consecutive enrolment of a large, multi-centre cohort of treated and untreated men with HG with similar demographic and health characteristics, power analyses to determine necessary sample size for the study, inclusion of standardised central laboratory measures of testosterone and PSA, and blinded adjudication of all mortalities and prostate biopsy findings by an 
Fig. 2 Prostate-specific antigen (PSA) level changes over time in testosterone-replacement therapy (TRT) treated and untreated men.

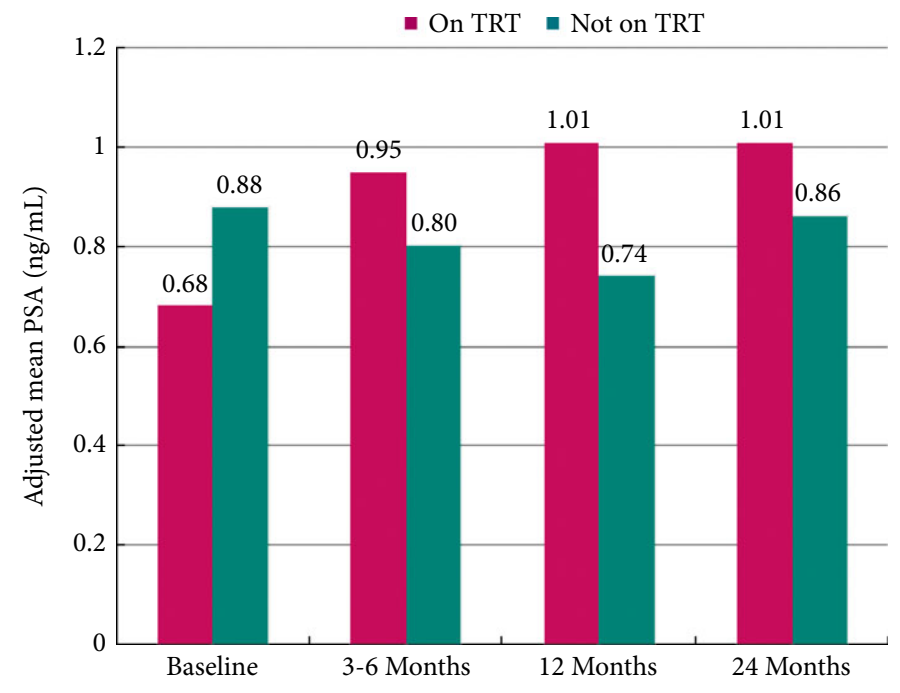

${ }^{1}$ PSA values from central laboratory not available after 24 months.

independent committee of experts. Multiple modes of TRT administration were permitted in RHYME, which increases variability in the data, but contributes positively to the clinical meaningfulness and generalisability of our present findings. Finally, we achieved high rates of retention and treatment compliance in the registry, which adds further to the validity of our findings.
Study limitations should also be noted. An important limitation is the absence of standard urodynamic measures of prostate function or volume. Given the observational design of the registry, these measures were only performed at the discretion of the treating physician and were not routinely included. Additionally, dihydrotestosterone levels and more distal testosterone metabolites were not assessed in RHYME. Men with a prior history of TRT or prostate cancer were excluded by design and further studies of TRT in these patients are needed. Although men receiving TRT were similar in age, demographic and health characteristics to untreated men in our cohort prior to treatment, we cannot exclude potential confounding due to selection biases or other unmeasured variables. On the other hand, the wide age range, and presence of multiple comorbidities in our cohort support the clinical relevance and generalisability of our present findings.

\section{Conclusion}

In the present longitudinal disease registry of 999 men with HG in six European countries, no evidence was seen of increased prostate cancer rates or LUTS/BPH progression in men receiving TRT compared with those who were untreated. Prostate cancer incidence rates in RHYME were similar to rates reported in large population studies and with findings from other single country or single product registries. The PSA level was minimally affected and slight improvements in voiding symptoms were seen in our present study in men on

Table 4 Changes in prostate-specific antigen (PSA) level and International Prostate Symptom Score (IPSS): longitudinal modelling of treatment and time effects.

\begin{tabular}{|c|c|c|c|c|c|c|}
\hline & \multicolumn{2}{|c|}{ Unadjusted } & \multicolumn{2}{|l|}{ Age-adjusted } & \multicolumn{2}{|c|}{ Fully adjusted } \\
\hline & $\begin{array}{c}\% \text { Change per unit } \\
(95 \% \text { CI) }\end{array}$ & $P$ & $\%$ Change per unit $(95 \%$ CI) & $P$ & $\begin{array}{l}\% \text { Change per } \\
\text { unit }(\mathbf{9 5 \%} \mathbf{C l})\end{array}$ & $\mathbf{P}$ \\
\hline \multicolumn{7}{|c|}{ Central laboratory PSA level, $\mathrm{ng} / \mathrm{mL}(n=752)^{*, \dagger}$} \\
\hline Treatment status & $21.4(13.8,29.4)$ & $<0.001$ & $21.5(14.0,29.6)$ & $<0.001$ & $20.3(12.1,29.2)$ & $<0.001$ \\
\hline Time (per month follow-up) & $0.0(-0.5,0.6)$ & 0.33 & $0.0(-0.6,0.6)$ & 0.36 & $-0.0(-0.6,0.6)$ & 0.47 \\
\hline Treatment status $\times$ time & $0.3(-0.4,0.9)$ & 0.46 & $0.3(-0.4,1.0)$ & 0.39 & $0.3(-0.4,1.1)$ & 0.38 \\
\hline \multicolumn{7}{|l|}{ IPSS $(n=896)^{*}$} \\
\hline Treatment status & $-6.0(-10.6,-1.2)$ & 0.01 & $-6.0(-10.5,-1.1)$ & 0.02 & $-7.1(-11.6,-2.3)$ & 0.004 \\
\hline Time (per month follow-up) & $0.0(-0.4,0.4)$ & 0.23 & $0.0(-0.4,0.4)$ & 0.23 & $0.1(-0.2,0.5)$ & 0.09 \\
\hline Treatment status $\times$ time & $0.2(-0.2,0.6)$ & 0.33 & $0.2(-0.2,0.7)$ & 0.26 & $0.1(-0.3,0.5)$ & 0.62 \\
\hline \multicolumn{7}{|c|}{ IPSS obstructive sub-score $(n=913)^{\S}$} \\
\hline Treatment status & $-3.1(-8.0,2.1)$ & 0.23 & $-3.1(-8.0,2.1)$ & 0.24 & $-3.0(-8.8,3.1)$ & 0.33 \\
\hline Time (per month follow-up) & $0.4(0.0,0.8)$ & $<0.001$ & $0.4(-0.0,0.8)$ & $<0.001$ & $0.5(0.1,0.9)$ & $<0.001$ \\
\hline Treatment status $\times$ time & $-0.1(-0.5,0.4)$ & 0.82 & $-0.0(-0.5,0.4)$ & 0.90 & $-0.1(-0.6,0.4)$ & 0.61 \\
\hline \multicolumn{7}{|c|}{ IPSS irritative sub-score $(n=910)^{\uparrow}$} \\
\hline Treatment status & $-7.0(-10.9,-3.0)$ & $<0.001$ & $-6.9(-10.8,-2.9)$ & $<0.001$ & $-7.9(-11.7,-3.9)$ & $<0.001$ \\
\hline Time (per month follow-up) & $-0.2(-0.5,0.1)$ & 0.60 & $-0.2(-0.5,0.1)$ & 0.59 & $-0.1(-0.4,0.2)$ & 0.98 \\
\hline Treatment status $\times$ time & $0.3(-0.1,0.6)$ & 0.11 & $0.3(-0.0,0.7)$ & 0.08 & $0.2(-0.1,0.6)$ & 0.21 \\
\hline
\end{tabular}

${ }^{*}$ Numbers vary for variables with missing data or indeterminate laboratory findings. ${ }^{\dagger}$ Model covariates: Age at consent, Country, Modified Charlson Comorbidity Index, Central laboratory LH $\geq 7.6 \mathrm{IU} / \mathrm{L}$, Self-reported health, Central laboratory blood draw time (am), Physician-reported urological disorder, $\alpha$-blockers, Other BPH medications, BMI. ${ }^{\star}$ Age at consent, Country, Self-reported health, Physician-reported urological disorder, Physician-reported depression/anxiety/other psychiatric disorder, $5 \alpha$-reductase inhibitors, $\alpha$-blockers, Other BPH medications, Anti-hypertensive medications, Lipid lowering medications. ${ }^{\S}$ Age at consent, Country, Central laboratory LH $\geq 7.6$ IU/L, Site specialty, Self-reported health, Physician-reported urological disorder, Physician-reported depression/anxiety/other psychiatric disorder, $5 \alpha$-reductase inhibitors, Thiazide diuretics, $\alpha$-blockers, Other BPH medications. "Age at consent, Country, Months from HG diagnosis to consent, Self-reported daily hard physical work, Self-reported health, Physician-reported urological disorder, Physician-reported depression/anxiety/other psychiatric disorder, $\alpha$-blockers, Anti-hypertensive medications, Lipid lowering medications. 
Fig. 3 International Prostate Symptom Score (IPSS) changes over time in testosterone-replacement therapy (TRT) treated and untreated men.

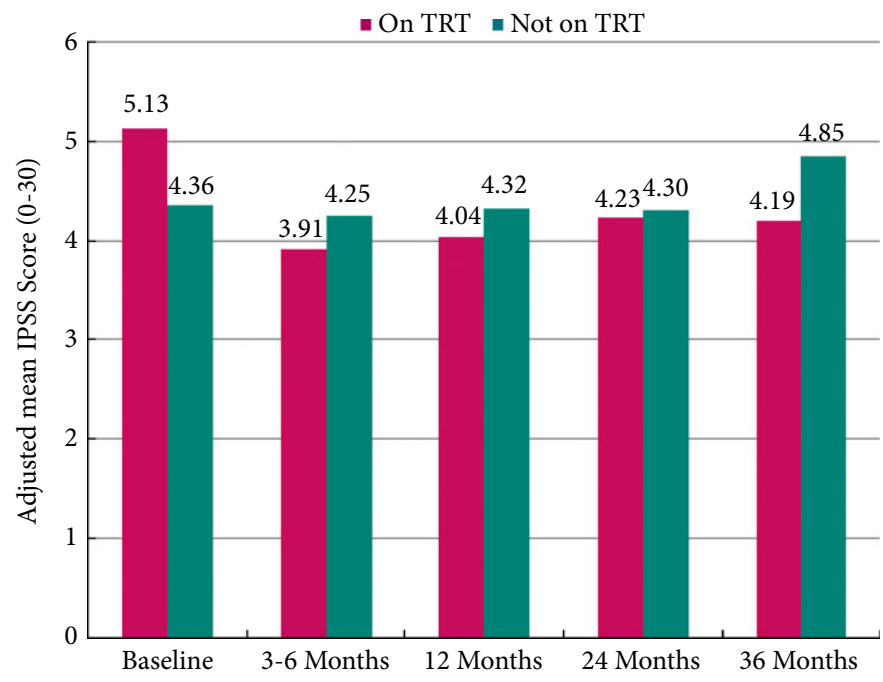

TRT. These findings warrant confirmation in further longterm, registries or randomised trials.

\section{Acknowledgements}

We gratefully acknowledge the outstanding contributions of RHYME investigators at the following sites: University of Florence, Italy, M. Maggi; University Hospital Halle, Germany, H. Behre; VU Medical Center, The Netherlands, E. Meuleman; Erasmus MC Rotterdam, Netherlands, G. Dohle; Karolinska University Hospital, Sweden, S. Arver; Manchester Royal Infirmary, UK, F. Wu; Private Practice of Urology/Andrology, Germany, H. Porst; Barnsley Hospital NHS Foundation Trust, UK, T.H. Jones; Royal Victoria Infirmary, UK, R. Quinton; Sapienza University of Rome, Italy, A. Lenzi; Royal Free Hampstead NHS, UK, PM. Bouloux; Carlos Haya University Hospital, Spain, A.M. Morales; Holly Cottage Clinic, UK, G. Hackett; Urohälsan i Skövde, Sweden, P. Stroberg; University of Parma, Italy, M. Maggio; Hospital Virgen del Rocio, Spain, N. Cruz; Ospediali Riuniti - Ancona, Italy, G. Balercia; Segeberger Kliniken, Germany, A. Yassin; Amstelland Hospital, Netherlands, C. Reisman; Fundacio Puigvert, Spain, L. Bassa; Hesperia Hospital, Italy, E. Pescatori; Hospital Universitario Puerta de Hierro-Majadahonda, Spain, J.I. Martinez Salamanca; Hospital Universitario 12 Octubre, Spain, J. Romero Otero; Evangelisches Krankenhaus Herne, Germany, F. Jockenhoevel; Andros Mens Health Institutes, Netherlands, F. Debruyne. Valuable assistance was provided by Ms. Juli Martha, Madhavi Kamma, Blandyna Williams and other research staff at NERI. We acknowledge guidance and support from Drs. Farid Saad, Albert Radlmaier, and Andreas Mattern at Bayer Healthcare.

\section{Funding Support}

Research support was provided by an unrestricted grant from Bayer Healthcare.

\section{Conflicts of Interest}

Frederick C.W. Wu has grants from Besins Healthcare and Eli Lilly, and personal fees from Besins Healthcare. Mario Maggi has grants and personal fees from Bayer Healthcare, Eli Lilly, Menarini, Prostrakan and Intercept. Glenn R. Cunningham reports grants and personal fees from AbbVie, personal fees from Apricus, Besins, Clarus Therapeutics, Endo Pharma, Ferring, Eli Lilly, Lipocine, Pfizer, Purdue Pharma and Repros Therapeutics during the conduct of the study. Thomas $\mathrm{H}$. Jones reports grants and personal fees from Bayer Healthcare, Besins Healthcare and Prostrakan, personal fees from Clarus Therapeutics, Mereo Biopharma, Eli Lilly, and MSD outside the submitted work. Raymond C. Rosen has grants from Bayer Healthcare, Besins Healthcare, and Eli Lilly, and personal fees from Apricus. Hermann M. Behre, Frans M.J. Debruyne, Hozefa A. Divan, Geoffrey Hackett, Eric Meuleman, Antonio Martin-Morales, Hartmut Porst, Claus G. Roehrborn, Fritz H. Schröder, and Olivia A. Wheaton have nothing to disclose.

\section{References}

1 Araujo AB, Esche GR, Kupelian V et al. Prevalence of symptomatic androgen deficiency in men. J Clin Endocrinol Metab 2007; 92: 4241-7

2 Wu FC, Tajar A, Beynon JM et al. Identification of late-onset hypogonadism in middle-aged and elderly men. N Engl J Med 2010; 363: 123-35

3 Dhindsa S, Miller M, McWhirter C et al. Testosterone concentrations in diabetic and nondiabetic obese men. Diabetes Care 2010; 33: 1186-92

4 Mulligan T, Frick MF, Zuraw QC, Stemhagen A, McWhirter C. Prevalence of hypogonadism in males aged at least 45 years: the HIM study. Int J Clin Pract 2006; 60: 762-9

5 Bhasin S, Cunningham GR, Hayes FJ et al. Testosterone therapy in men with androgen deficiency syndromes: an Endocrine Society clinical practice guideline. J Clin Endocrinol Metab 2010; 95: 2536-59

6 Dohle GR, Arver S, Bettocchi C, Jones TH, Kliesch S, Punab M. Guidelines on Male Hypogonadism, 2015. European Association of Urology. Available at: http://uroweb.org/wp-content/uploads/EAUGuidelines-Male-Hypogonadism-2015.pdf. Accessed July 2016

7 Lunenfeld B, Mskhalaya G, Zitzmann M et al. Recommendations on the diagnosis, treatment and monitoring of hypogonadism in men. Aging Male 2015; 18: 5-15

8 Guo C, Gu W, Liu M et al. Efficacy and safety of testosterone replacement therapy in men with hypogonadism: a meta-analysis study of placebo-controlled trials. Exp Ther Med 2016; 11: 853-63

9 Gannon JR, Walsh TJ. Testosterone and sexual function. Urol Clin North Am 2016; 43: 217-22

10 Hackett G. An update on the role of testosterone replacement therapy in the management of hypogonadism. Ther Adv Urol 2016; 8: 147-60

11 Corona G, Giagulli VA, Maseroli E et al. Therapy of endocrine disease: testosterone supplementation and body composition: results from a metaanalysis study. Eur J Endocrinol 2016; 174: R99-116 
12 Francomano D, Lenzi A, Aversa A. Effects of five-year treatment with testosterone undecanoate on metabolic and hormonal parameters in ageing men with metabolic syndrome. Int J Endocrinol 2014; 2014: 527470

13 Saad F, Yassin A, Doros G, Haider A. Effects of long-term treatment with testosterone on weight and waist size in 411 hypogonadal men with obesity classes I-III: observational data from two registry studies. Int $J$ Obes (Lond) 2016; 40: 162-70

14 Traish AM. Testosterone and weight loss: the evidence. Curr Opin Endocrinol Diabetes Obes 2014; 21: 313-22

15 Snyder PJ, Bhasin S, Cunningham GR et al. Effects of testosterone treatment in older men. $N$ Engl J Med 2016; 3747: 611-24

16 Haider A, Zitzmann M, Doros G, Isbarn H, Hammerer P, Yassin A. Incidence of prostate cancer in hypogonadal men receiving testosterone therapy: observations from 5-year median followup of 3 registries. J Urol 2015; 193: 80-6

17 Schroder FH, Hugosson J, Carlsson S et al. Screening for prostate cancer decreases the risk of developing metastatic disease: findings from the European Randomized Study of Screening for Prostate Cancer (ERSPC). Eur Urol 2012; 62: 745-52

18 Cui Y, Zong H, Yan H, Zhang Y. The effect of testosterone replacement therapy on prostate cancer: a systematic review and meta-analysis. Prostate Cancer Prostatic Dis 2014; 17: 132-43

19 Kathrins M, Doersch K, Nimeh T, Canto A, Niederberger C, Seftel A. The relationship between testosterone replacement therapy and lower urinary tract symptoms: a systematic review. Urology 2016; 88: 22-32

20 Kohn TP, Mata DA, Ramasamy R, Lipshultz LI. Effects of testosterone replacement therapy on lower urinary tract symptoms: a systematic review and meta-analysis. Eur Urol 2016; 69: 1083-90

21 Rosen RC, Wu FC, Behre HM et al. Registry of Hypogonadism in Men (RHYME): design of a multi-national longitudinal, observational registry of exogenous testosterone use in hypogonadal men. Aging Male 2013; 16: $1-7$

22 Grubb RL, Pinsky P, Prorok PC, Andriole GL. Screening for cancer: lessons learned from the prostate, lung, colorectal, and ovarian cancer screening trial. Eur Urol 2015; 68: 545-6

23 Thompson IM, Goodman PJ, Tangen CM et al. The influence of finasteride on the development of prostate cancer. N Engl J Med 2003; 349: $215-24$

24 Welch HG, Fisher ES, Gottlieb DJ, Barry MJ. Detection of prostate cancer via biopsy in the Medicare-SEER population during the PSA era. $J$ Natl Cancer Inst 2007; 99: 1395-400

25 Haider A, Haider KS, Doros G, Traish A. PD09-06 Prostate cancer is less frequent and severe in hypogonadal men treated adequately with testosterone undecanoate injections (TU) for up to 8 years compared to untreated hypogonadal controls. J Urol 2016; 195 (Suppl.): e236 (Abstract).

26 Yassin DJ, El Douaihy Y, Yassin AA, Kashanian J, Shabsigh R, Hammerer PG. Lower urinary tract symptoms improve with testosterone replacement therapy in men with late-onset hypogonadism: 5-year prospective, observational and longitudinal registry study. World J Urol 2014; 32: 1049-54

27 Francomano D, Ilacqua A, Bruzziches R, Lenzi A, Aversa A. Effects of 5 -year treatment with testosterone undecanoate on lower urinary tract symptoms in obese men with hypogonadism and metabolic syndrome. Urology 2014; 83: 167-73
28 Zitzmann M, Mattern A, Hanisch J, Gooren L, Jones H, Maggi M. IPASS: a study on the tolerability and effectiveness of injectable testosterone undecanoate for the treatment of male hypogonadism in a worldwide sample of 1,438 men. J Sex Med 2013; 10: 579-88

29 Miner MM, Bhattacharya RK, Blick G, Kushner H, Khera M. 12-month observation of testosterone replacement effectiveness in a general population of men. Postgrad Med 2013; 125: 8-18

30 Behre HM, von Eckardstein S, Kliesch S, Nieschlag E. Long-term substitution therapy of hypogonadal men with transscrotal testosterone over 7-10 years. Clin Endocrinol (Oxf) 1999; 50: 629-35

31 Andriole GL, Bostwick D, Brawley OW et al. The effect of dutasteride on the usefulness of prostate specific antigen for the diagnosis of high grade and clinically relevant prostate cancer in men with a previous negative biopsy: results from the REDUCE study. J Urol 2011; 185: 126-31

32 Schenk JM, Till C, Hsing AW et al. Serum androgens and prostate cancer risk: results from the placebo arm of the Prostate Cancer Prevention Trial. Cancer Causes Control 2016; 27: 175-82

33 Xu X, Chen X, Hu H, Dailey AB, Taylor BD. Current opinion on the role of testosterone in the development of prostate cancer: a dynamic model. BMC Cancer 2015; 15: 806

34 Park J, Cho SY, Jeong SH, Lee SB, Son H, Jeong H. Low testosterone level is an independent risk factor for high-grade prostate cancer detection at biopsy. BJU Int 2015; 118: 230-35

35 Baillargeon J, Kuo Y-F, Fang X, Shahinian VB. Long-term exposure to testosterone therapy and the risk of high grade prostate cancer. J Urol 2015; 194: 1612-6

36 Neuzillet $\mathrm{Y}$, Raynaud JP, Lebret $\mathrm{T}$ et al. Obesity and hypogonadism are associated with an increased risk of predominant Gleason 4 pattern on radical prostatectomy specimen. Horm Mol Biol Clin Invest 2015; 22: $101-9$

37 Davidson E, Morgentaler A. Testosterone therapy and prostate cancer. Urol Clin North Am 2016; 43: 209-16

38 Grech A, Breck J, Heidelbaugh J. Adverse effects of testosterone replacement therapy: an update on the evidence and controversy. Ther Adv Drug Saf 2014; 5: 190-200

39 Kava BR. To treat or not to treat with testosterone replacement therapy: a contemporary review of management of late-onset hypogonadism and critical issues related to prostate cancer. Curr Urol Rep 2014; 15: 422

40 Carson CC, Kirby R. Prostate cancer and testosterone replacement therapy: what is the risk? J Urol 2015; 194: 1527-8

41 Dreyer NA, Garner S. Registries for robust evidence. JAMA 2009; 302: $790-1$

Correspondence: Raymond C. Rosen, PhD, New England Research Institutes, Inc., 480 Pleasant Street, Watertown, Massachusetts 02472, USA.

\section{e-mail: RRosen@neriscience.com}

Abbreviations: BMI, body mass index; HG, hypogonadism; RHYME, Registry of Hypogonadism in Men; RR, rate ratio; TRT, testosterone-replacement therapy. 